\title{
THE RADIOLOGY OF PRIMARY ATYPICAL PNEUMONIA
}

\author{
BY \\ P. W. VERCC* \\ From the Institute of Medical and Veterinary Science, Adelaide, and the Department of Experimental Medicine, \\ University of Adelaide
}

The pulmonary changes accompanying " primary atypical pneumonia, aetiology unknown" have been of considerable interest to radiologists and physicians over the past decade. Characteristic varieties of pulmonary change occurring in this illness have been the subject of many reports in the literature, although few studies have been accompanied by an adequate aetiological investigation.

This condition may be indistinguishable clinically from many other diseases which occur in both epidemic and endemic form. Notable among these are infections with influenza virus A or B (Ziegler, Curnen, and Mirick, 1947), infection with the psittacosis group of viruses (Treuting and Olson, 1944), " $Q$ " fever (Feinstein, Yesner, and Marks, 1946), infectious mononucleosis (Wechsler, Rosenblum, and Sills, 1946) and coccidioidomycosis (Rakofsky and Knickerbocker, 1946). Differentiation is made, possibly by isolation of the causative agent, or by demonstration of a rise of titre in the convalescent serum of antibody or certain other properties of the serum, or by the use of intracutaneous sensitivity tests.

The investigations of the Commission on Acute Respiratory Diseases (1944), of Eaton, Meiklejohn, and van Herick (1945), and of the United States Navy Research Unit at the Rockefeller Institute Hospital in New York (Curnen and others, 1945) have confirmed, by the correlation of clinical, radiological, and aetiological investigations, the findings of many previous observers. In the transmission to human volunteers of the naturally occurring illness by inoculation of filtered throat washings and sputum, the Commission (1946) has established a virus or viruses as the causative agent, and has provided a basis on which the radiological study of the disease may be founded.

In these reports, the early radiological manifestations in most cases of the naturally occurring disease were stated to be an increase in size of one or both hilar shadows, increasing perihilar infiltration, and extension of the shadow toward the periphery in the shape of a fan. Less commonly the early lesion

\footnotetext{
* This work was aided by a grant from the National Health and Medical Research Council of Australia.
}

appeared to lie peripherally in the lung and extension took place towards the hilum.

However, in the illness transmitted experimentally, pulmonary change became apparent from the second to the fifth day after onset, and the earliest sign was a local increase in the density of the lung markings without concomitant hilar involvement. This was most commonly seen at the lung bases, best visualized by anterior-oblique films, and the infiltration appeared either linear as an exaggeration of the basilar truncal markings, or as patches of soft irregular density. Frequently the latter were located in the most peripheral and dependent portions of the lung, the costo-phrenic sulci, and connexion with the normal hilar shadow did not appear to be continuous. In the remaining patients perihilar infiltration with or without parenchymal involvement was the earliest manifestation.

Subsequently, in both the naturally occurring and the experimentally transmitted disease, in some cases the infiltration remained limited to the peripheral portions of one or both lower lobes, and the hilar regions were not abnormal at any time, or the early peribronchial infiltration appeared to spread centrally toward the hilum with concomitant radial spread within the lower lobe; in others the perihilar infiltration became increasingly apparent, and spread occurred in the peripheral portion of one or more lobes in a fan shape, with the greatest density at the hilum.

Extraordinary variation in the density of the infiltration was noted, although usually it appeared soft and either granular or homogeneous. The lung markings were usually visible through the opacity, although their outlines were frequently indistinct. The borders of the areas of infiltration were commonly ill-defined and irregular, fading into normal lung tissue. The infiltration was rarely of sufficient density to resemble that of pneumococcal pneumonia. Distinct but delicate " pencilling" at the site of the interlobar fissures frequently suggested pleural involvement. Radiological features suggesting an abnormal accumulation of pleural fluid were uncommon, and "plate-like" atelectasis was observed on occasions during convalescence. In 
most patients, the process appeared to be confined to a local area, most frequently to one of the lower lobes, and in particular to one of the cardiophrenic angles. Spread of the lesion often occurred within a lobe or in an adjoining lobe, and multiple lobe involvement was frequent. In some cases the lesion was confined to the hilar region.

Occasionally, the lesions lasted only a few days, but usually they progressed, and then underwent slow resolution over a period of one to three weeks. Resolution was observed to occur in several ways. In most instances it proceeded from the periphery of the lung toward the hilum, but occasionally in the reverse direction. Also progressive reduction in the size and diminution in density of the affected area was observed until no further evidence of consolidation remained. In many instances, during the process of resolution, the affected area assumed a diffusely mottled appearance. Frequently, after all the pulmonary involvement was thought to have disappeared the broncho-vascular markings remained prominent. The enlarged hilar shadows often persisted for several weeks.

When the infiltration was mottled it occasionally presented the appearance of small abscess cavities. Infiltrations radiating from the hilum with involvement of the upper lobe resembled tuberculosis, whereas other lesions, especially in the lower lobes, simulated bronchiectasis. In several cases of experimentally transmitted illness, the pulmonary opacities were small, discrete, and nodular in the early stage, later enlarging in size and becoming patchy and confluent. This type of infiltration might resemble miliary tuberculosis.

These observers have emphasized that other forms of pneumonia could not be distinguished from primary atypical pneumonia on the basis of radiographic evidence alone, and that a diagnosis of primary atypical pneumonia was not justified unless made in conjunction with clinical and laboratory findings.

Of particular interest is that form of primary atypical pneumonia in which the pulmonary opacities resemble miliary tuberculosis. Scadding (1937) described four cases of " disseminated focal pneumonia " and was impressed by the resemblance of the infiltration to tuberculosis. Radiological manifestations consisted of " areas of diffuse rather coarse mottling, in foci varying from about 2 to $5 \mathrm{~mm}$. in diameter "present in more than one lobe in three patients, and resolution was slow in all but one. Scadding cited descriptions of appearances attributed to bronchopneumonia in " miliary" foci by radiologists in American and German literature; the chief point of discussion in these reports was the radiological diagnosis distinguishing them from pulmonary tuberculosis. Several of these reports, where the clinical features were presented in sufficient detail, described in common with his own series a similar radiological picture, namely a gradual onset with predominantly constitutional symptoms, and a prolonged course with eventual complete resolution. Reiman (1938) reported a series of eight cases, which presented a radiological picture and course strikingly similar to those of two of Scadding's patients. All the patients were adults, and a mild infection of the upper respiratory tract was followed by severe diffuse atypical pneumonia, and in two patients by encephalitis.

Patients presenting similar radiological features, with severe and prolonged illness, were reported by Kneeland and Smetana in 1940. Such cases have since occurred, usually as a minority in epidemics of primary atypical pneumonia. McCarthy (1943) noted that these patients were extremely ill. Lewis and Lusk (1944) reported such cases as a " bronchoalveolar phase," and suggested that the radiographic manifestations could be explained pathologically by small areas of atelectasis and alveolar exudation intermingled with emphysematous areas. Showacre, Wightman, and Moore (1944) recorded their experience with probable primary atypical pneumonia over a decade, and emphasized that the radiographic pattern varied from one season to another and at times during the same season.

Eaton, Meiklejohn, and van Herick $(1942,1945)$ reported the isolation of a new virus from cases of primary atypical pneumonia; they apparently transmitted an infectious agent to cotton rats from a fatal case of a very diffuse " miliary" pneumonia. Jamison (1945) recorded further cases of primary atypical pneumonia; in two patients the infiltration was of a finely nodular or patchy type, scattered uniformly in both lungs. Löffler and Moeschlin (1946) reported a further series of seven such cases, four of which were fatal. In the sera of three patients of the four tested, cold agglutinins developed.

Most descriptions of this form of primary atypical pneumonia, with the exception of that of Scadding (1937), suggest that resolution is early and complete. In his patients, resolution tended to be slow and irregularly delayed, and in one was not complete for at least 12 weeks from the onset.

\section{Pathology}

Golden (1944) has reviewed the pathological anatomy of necropsy material from cases considered to be examples of primary atypical pneumonia. He found that the pulmonary lesions which all patients had in common could be summarized as follows. 
1. There was acute bronchiolitis, focally distributed, in which desquamation of the mucosal surfaces occurred early.

2. The lumens of such bronchioles contained frank pus, mucoid fluid, and desquamated epithelial clusters or single cells, sometimes in an advanced stage of disintegration.

3. Bacteria in small numbers, and not of uniform type, could be demonstrated in the bronchiolar pus in some cases; in most instances none could be found.

4. The bronchioles were dilated, sometimes greatly, even in patients who had died early in the disease.

5. The walls of such bronchioles were infiltrated chiefly with mononuclear cells, which extended radially into the regional interstitial tissues of the lung around the bronchioles, in the alveolar walls, and in the pulmonary septums.

6. The alveoli either contained air or were collapsed, and differed from those involved in bronchopneumonia and lobar pneumonia in being relatively free of polymorphonuclear leucocytic exudate.

7. Such areas failed to reveal microorganisms on tissue section.

8. With the advent of secondary bacterial invasion the gross and microscopic pictures were altered: in some patients there were areas of acute interstitial pneumonia adjacent to zones of typical bronchopneumonia or pulmonary abscess. In fact, unless there was such a partition of the lesions, it was impossible to state from the pathological examination that there were really two co-existing types of lesion in a given case.

Meiklejohn (1947) has suggested that Golden's account of the pathological features of primary atypical pneumonia be accepted with caution, as the aetiological investigations in some cases were insufficient.

Parker, Jolliffe, and Finland (1947) reported the necropsy findings in eight patients, all of whom had illness characteristic of the severe and extensive type of primary atypical pneumonia. In every case radiography showed a soft miliary type of density which eventually spread to involve most of the lung fields. Two of these patients, in one of whom a significant complement fixation titre for psittacosis was found, had a diffuse, bullous type of erythema multiforme. Attempts to isolate a virus from five patients were not successful. The duration of the illness varied from 13 to 31 days. Histologically, the characteristic changes in the lungs were a mononuclear type of alveolar exudate with swelling and proliferation of the alveolar lining cells. Interstitial infiltration, for the most part by plasma cells, was constant and conspicuous in the walls of the bronchioles and around the blood vessels, and frequently extended into the walls of the alveoli. Oedema of the septums was prominent, thrombi in the smaller arteries and veins were frequent, and hyaline membranes were found in the alveoli in approximately half the patients. In contrast to the observations of Golden, the bronchioles, with rare exceptions, showed no evidence of injury and contained no exudate in areas free from secondary bacterial infection. Where there was secondary bacterial infection, the lumens of the bronchioles contained many polymorphonuclear leucocytes, cocci, and often some mucus. Secondary bacterial invasion seemed to be the rule. In some, but not all such cases, the alveoli contained polymorphonuclear leucocytes and sometimes fibrin. Organization of the alveolar and bronchiolar exudates was found in most patients but was not extensive.

Parker and others (1947) agree with Golden that the pulmonary lesions, whilst resembling those found in psittacosis, are not identical. In psittacosis the alveolar exudate contains considerably more fibrin and red blood cells, and interstitial infiltration is not so conspicuous a feature as in primary atypical pneumonia.

Golden considered that descriptions of essentially the same lesions that occur in primary atypical pneumonia are to be found among reports of influenzal pneumonia during the 1918-19 pandemic, particularly when death occurred within the first five days of illness. When the clinical duration of the illness was greater than five to seven days in the pandemic, secondary infection was the rule. Parker, Jolliffe, and Finland (1947) found in influenza that secondary staphylococcal invasion caused a severe disease, fatal either in a few days or after two weeks or more. In the rapidly fatal cases the most prominent features were oedema and haemorrhage; extensive necrotizing tracheobronchitis and multiple pulmonary abscesses were also seen. In cases of longer duration the lungs showed extensive fibrosis and cavity formation. No lesions of such extent occurred in their examples of primary atypical pneumonia.

Measles may cause a similar acute interstitial pneumonia (Milles, 1945). McCordock and Muckenfuss (1933) have called attention to the tendency of viral pulmonary infections, particularly influenza and measles, to produce this type of pulmonary lesion. Other virus diseases may present comparable pulmonary lesions, e.g., chickenpox (Waring and others, 1942; Claudy, 1947), infectious mono- 
nucleosis (Allen and Kellner, 1947), lymphocytic chorio-meningitis (Smadel and others, 1942), and the primary virus pneumonia with cytoplasmic inclusion bodies reported by Adams (1941). Pertussis, a bacterial infection, is capable of producing an acute interstitial pneumonia, in which Haemophilus pertussis can be demonstrated in the sections. Diverse chemical and physical agents may produce similar lesions; for instance, the irritant war gases (Winternitz and others, 1920), $x$-radiation (McIntosh and Spitz, 1939), and hot and irritating vapour (Finland and others, 1946).

It is generally agreed that secondary infection by pathogenic bacteria may obscure the histological picture of pneumonia of virus origin at necropsy. Large doses of sulphonamides or penicillin are likely to have been given in fatal cases, and may well affect the important lesions due to secondary infection.

\section{MATERIAL}

In the course of an investigation into primary atypical pneumonia, aetiology unknown, conducted over a period of 14 months at the Royal Adelaide Hospital, 34 cases closely resembling this condition were admitted to the hospital. Investigations were of a satisfactory standard in only 14 of these patients, and the clinical and laboratory features of these have been reported in detail elsewhere (Verco, 1949). Of these 14 patients, 10 were female and 4 were male: their ages varied from 16 to 53 years. Most of them became ill during the period August, 1946 , to January, 1947, when there was a small epidemic of similar cases in Adelaide. The patients, with the exception of cases 103 and 128 , who lived in the same hostel and came from the same district as cases $102,105,109$, and 120 , were from widely separated areas, and all had been exposed to several possible sources of infection. No instance of primary atypical pneumonia occurred among the staff directly responsible for the care of these patients.

These cases presented remarkably similar clinical pictures. In several cases the illness began with mild upper respiratory symptoms, but in most the onset was insidious, with constitutional symptoms increasing in severity, to be followed shortly by an irritating cough, at first unproductive. Headache, often frontal, and irritatıng cough, at times paroxysmal, were conspicuous. Severe pleural pain did not occur. Many patients were severely ill, but the severity of the illness was suggested rather by the fever, the rapid pulse, and frequent respiration than by the general appearance and mental clarity. As the illness progressed, particularly when severe, the leucocyte count tended to rise, due mainly to an increase in the polymorphonuclear leucocytes. Subsidence of fever by lysis, and slowing of pulse and respiration were usually preceded by a noticeable improvement in the patient's condition. The illness was little influenced by the administration of sulphonamides and penicillin. It was not possible to predict accurately either the duration or the severity of the illness in any given case. All patients began to show clinical improvement, and resolution of pulmonary opacities began within a month of the onset. Convalescence was often protracted with asthenia and a mild cough.

Two patients died; case 108 from extensive involvement of both lungs by the pneumonia, case 120 from an extensive haemorrhagic leucoencephalitis and pneumonia (Fowler and French, 1949). In both patients, the pulmonary lesions had many features in common with the pathological anatomy described by Golden (1944).

Case 105 presented, in addition to pulmonary involvement, an acute haemolytic anaemia with leukaemoid features of the myeloid cells, meningeal symptoms, and an increased cellular content of the cerebrospinal fluid.

Sputa of nine patients were examined. Smears and cultures revealed the usual pharyngeal organisms, including both pneumococci and Gramnegative bacilli in cases 107 and 108, haemolytic streptococci in cases 110 and 124, and a coagulasepositive haemolytic staphylococcus in case 109 . In case 120 , the lungs were bacteriologically sterile at necropsy; no bacteriological studies were made post-mortem in case 108 . The sputum was not examined in cases 103 and 105 . In cases 102 and 104 the cough did not become productive until convalescence was established.

Sera were obtained from all patients except case 120. Ten patients developed cold agglutinins to a titre of $1: 32$ or greater. Sera from 12 patients were titrated for " $\mathrm{T}$ " agglutinins (Lind and McArthur, 1947), and eight showed titres of $1: 600$ or greater. In no case was the psittacosis complement fixation titre considered indicative of infection with the psittacosis group of viruses, nor did agglutination against Rickettsia burneti develop. Paired acute and convalescent phase sera from cases 105, 106, 110, and 124, and from 16 other cases of acute pulmonary infection admitted to the hospital during the period of this study, were titrated for content of antibody against influenza viruses $A$ and $B$. No evidence suggesting infection with the influenza viruses was obtained.

Intracutaneous tests with histoplasmin and coccidioidin (extracts of Histoplasma capsulatum and Coccidioides immitis) were performed in all except 
the two fatal cases, and were negative. The Mantoux reaction was negative in six and positive in four patients. The other two patients presented a change of Mantoux reaction from negative to positive. In case 124 this occurred at least four and a half months after the onset of the pneumonia, and indicated recent primary infection. In patient 121 the Mantoux test was negative in convalescence, but positive five months later; this was attributed either to recent infection, or to recovery from a period of anergy occasioned by a severe illness.

Follow-up examination of all patients yielded no evidence of active pulmonary or other forms of tuberculosis.

\section{Radiological Features}

The illness was, with few exceptions, well established by the time patients were admitted to hospital, and the opportunity to detect early pulmonary lesions did not arise. The severe course of the illness and rapid respirations frequently resulted in inferior films, which had to be taken with a portable apparatus. The character of the established pulmonary lesions divided the 14 patients into two groups.

Group I.-In the first group of six patients (Nos. $101,102,103,106,109$, and 124), the opacities tended to be compact and localized, as described in the majority of cases of primary atypical pneumonia. In serial films the appearance of the opacities differed in no way from those described previously in density, form, or distribution. The density varied from the degree associated with lobar pneumonia to a haze through which lung markings could be clearly seen. In form, variations from apparent lobar involvement to smaller, dense, fluffy opacities suggesting lobular pneumonia, or coarse short streaks of moderate density forming a network and scattered nodules $2-5 \mathrm{~mm}$. in diameter most dense at the centre, were seen. Accentuation of the normal lung markings and unduly prominent vascular markings were often present. The lesions were most frequently situated in the lower lobes. Frequently several forms of opacity were diffusely distributed in the same film.

In addition to the pulmonary opacities, enlargement of one hilar shadow, confirmed by return to normal in subsequent films, was present in three patients. In patients 101 and 124, there were opacities in the lower part of the left lung, and the left diaphragm was elevated. In patient 109, dense opacity of the lower half of the right lung, and a little infiltration at the base of the left lung in the postero-anterior (P.A.) film, were associated with elevation of the right diaphragm and shift of the heart to the right. A lateral film showed involvement of the middle lobe, of a large segment at the apex of the lower lobe, and there was scattered infiltration in the remainder of the lower lobe and in the lower portion of the upper lobe of the right lung.

In patients 102 and 103 the lower portions of both lungs were affected, more on the right, and accompanied by elevation of a portion of the left diaphragm in patient 102. In patient 106 there was infiltration of the posterior part of the left upper lobe, and collapse of the lingula.

Resolution was rapid after subsidence of the acute illness, usually within a month of onset. The opacities diminished in density and extent, to be replaced by small nodules and a network of coarse striae, with prominent vascular markings. This appearance was very similar to that of certain forms of pulmonary tuberculosis, and may be mimicked by other forms of pneumonia in resolution. In patient 101 , atelectatic plates were also present at this stage. The clearing of the infiltration, particularly if it had been fairly dense above an elevated hemi-diaphragm, as in patient 101 , now unexpectedly disclosed tenting of the diaphragm (Figs. 1, 2, and 3). This was usually situated about the middle part of the diaphragm, and was present in patients 102, 103 , and 106 also. In patient 101 , in addition to the tenting of the left diaphragm in this region, the first lateral view taken five months after onset

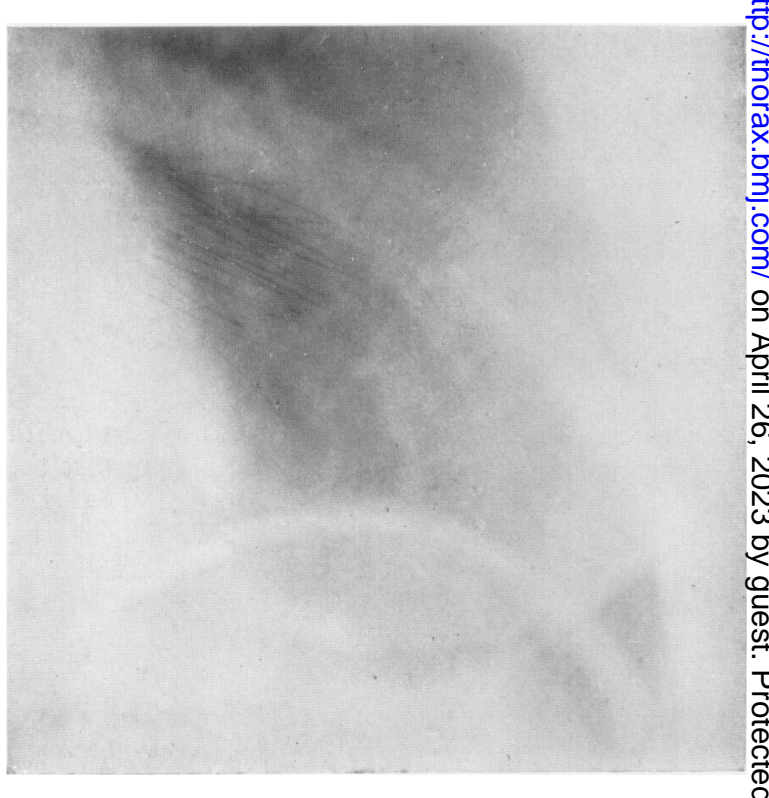

FIG. 1.-Case_. 101, P.A. view, August 24, 1945. Left diaphragm normal. 


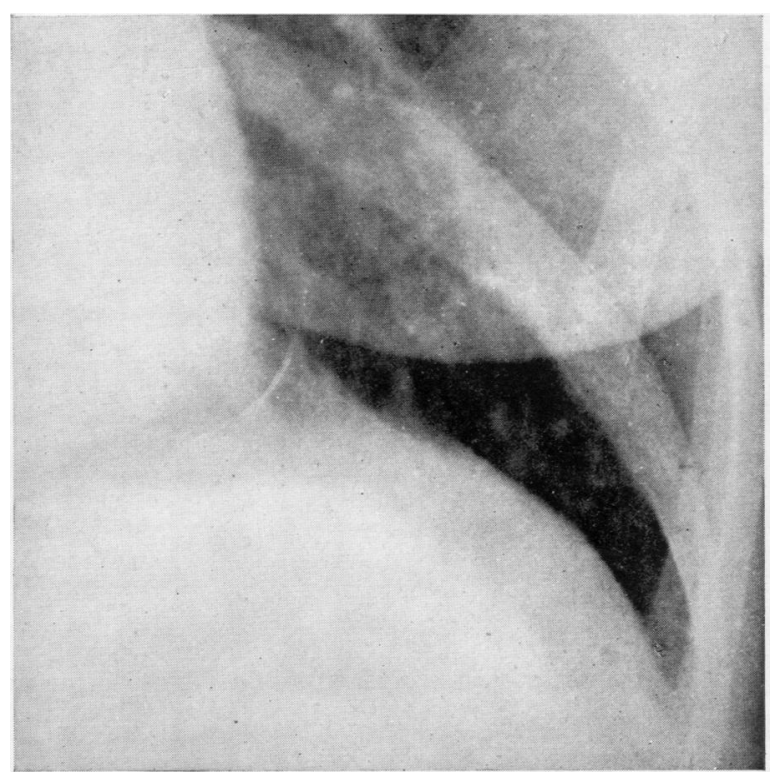

FIG. 2.-Case 101, P.A. view, July 7, 1947, 252 days after onset of illness, showing adhesions of medial portion of left diaphragm.

showed considerable thickening of the pleura against the lower part of the anterior chest wall. In the P.A. films this had been obscured by the cardiac shadow. Seventeen months after onset it

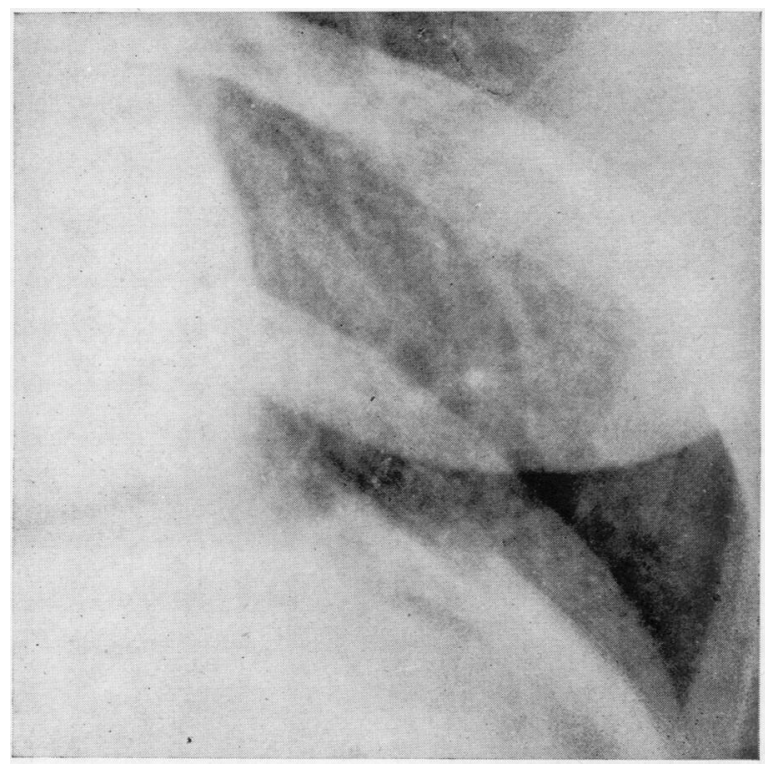

FIG. 3.-Case 101, P.A. view, March 10, 1948, 499 days after onset. Diaphragmatic adhesions less apparent. had diminished considerably in extent and the tenting of the left diaphragm was less noticeable. In some of these patients, but not all, there was evidence of previous tuberculous infection; the Mantoux test was positive in patient 103, and in patient 102 there were a few small pulmonary foci of doubtful calcification, with a negative $1: 1,000$ Mantoux test.

As resolution progressed further, the reticulation and nodules faded slowly, leaving accentuated lung and vascular markings in the affected areas, which gradually returned to normal on subsequent examination. In patient 109 , considerable resolution had occurred within 60 days of onset, but an area of scattered opacities persisted in the right middle lobe, associated with a cough productive of a small amount of mucoid sputum. This area of opacity, visible in both P.A. and lateral films, slowly faded unt 1 it had completely resolved 20 months after onset.

Group II.-The second group comprised the remaining eight patients, 104, 105, 107, 108, 120, 121 , and 128 . The course of the illness was generally more severe than in the first group, although it ran a moderate course in patients 104 and 105; two patients, 108 and 120, died. The quality of the films obtained in this group frequently reflected the severity of the illness, but the pulmonary lesions presented remarkable similarities in appearance and behaviour.

The opacities seen in this group resembled those described in similar cases by others. Drew, Samuel, and Ball (1943), in a series of 54 cases of primary atypical pneumonia found nine with multiple areas of patchy consolidation as described by Scadding (1937), and 18 with coarse reticulation and an overlay of haze. In the second group of the present series, "nodules" were scattered throughout the affected lung; they consisted of small round shadows, 2 to $5 \mathrm{~mm}$. in diameter, of moderate density at the centre, and without a clearly defined edge. They varied in size and density, were distributed unevenly, and remained discrete, although toward the latter part of the illness they appeared to have increased a little in size. In some cases the nodules formed aggregations, rarely larger than $1 \mathrm{~cm}$. in diameter, of regular or irregular outline, usually granular but sometimes homogeneous. Forming a background to these nodules was a network of streaks, denser t'ian the normal lung markings. Besides these nodules and network, the translucency of the affected lung was diminished, as though a light haze were cast over it.

In the majority of patients in this group the appearance of miliary nodules predominated, 

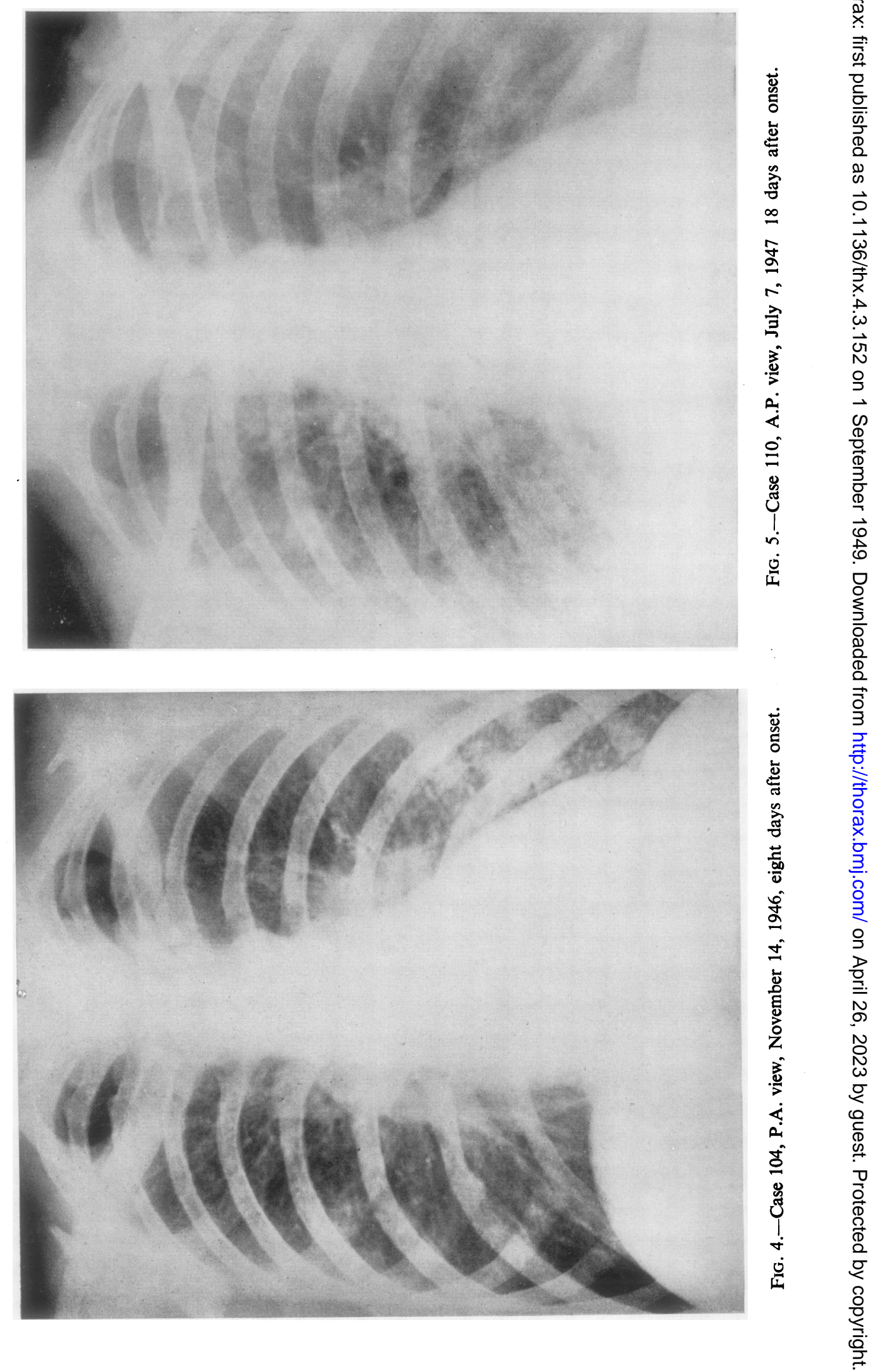


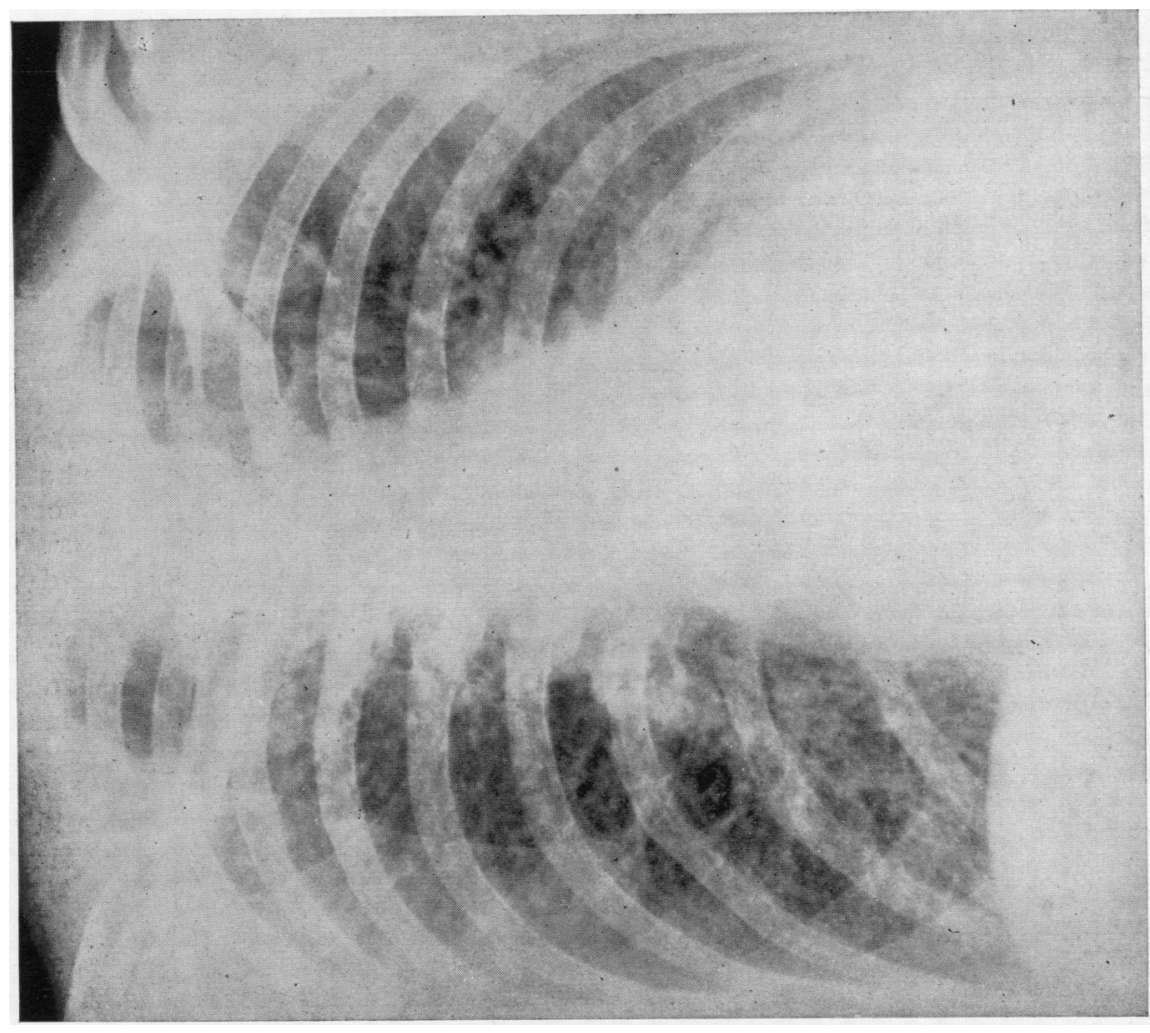

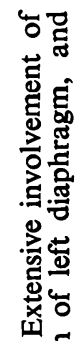

되 도

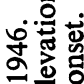

$+$

ब.

ป

छิ

이

थ

30

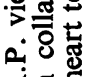

$<$ 동

ते $^{3}$

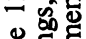

范至

1동융

它
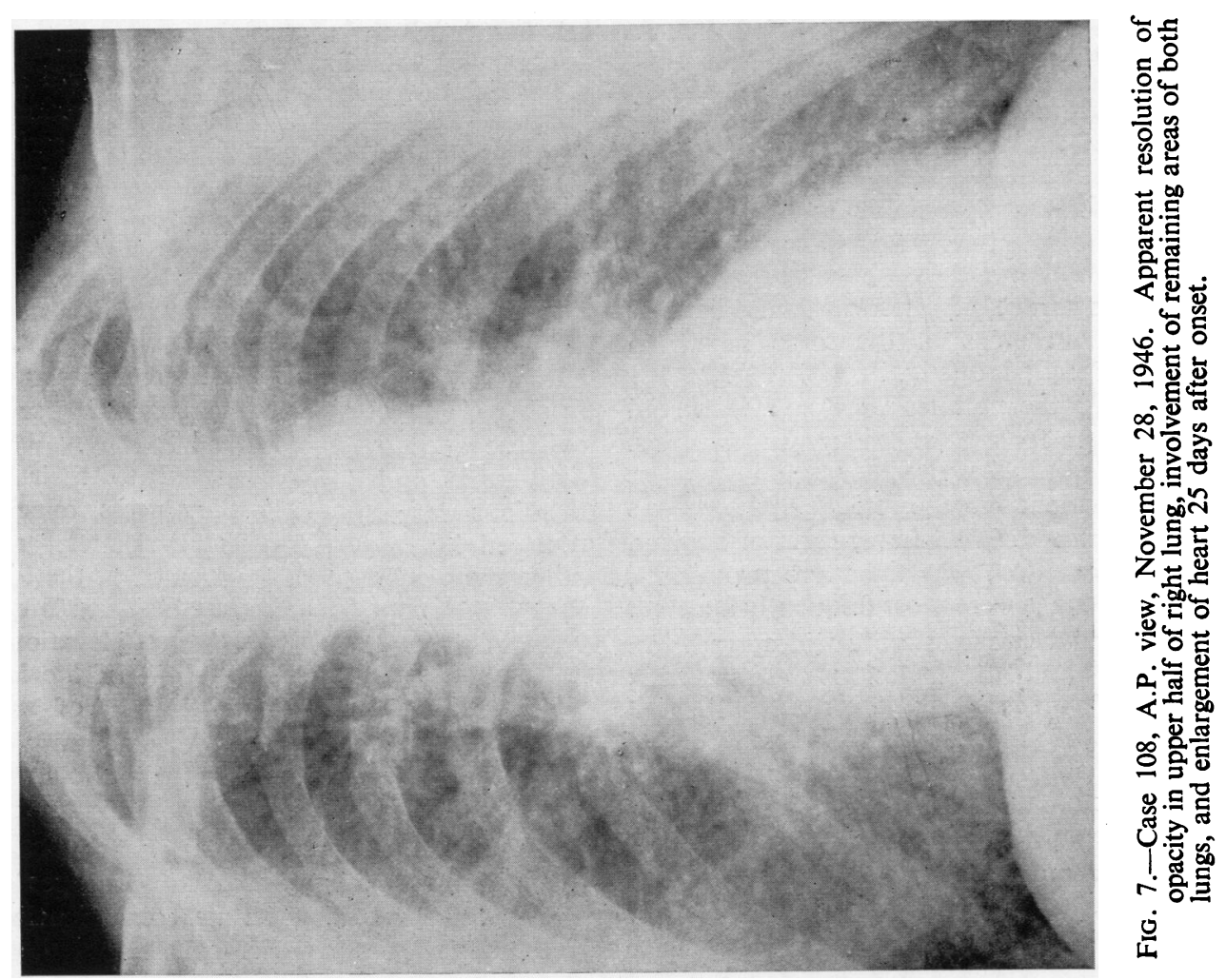


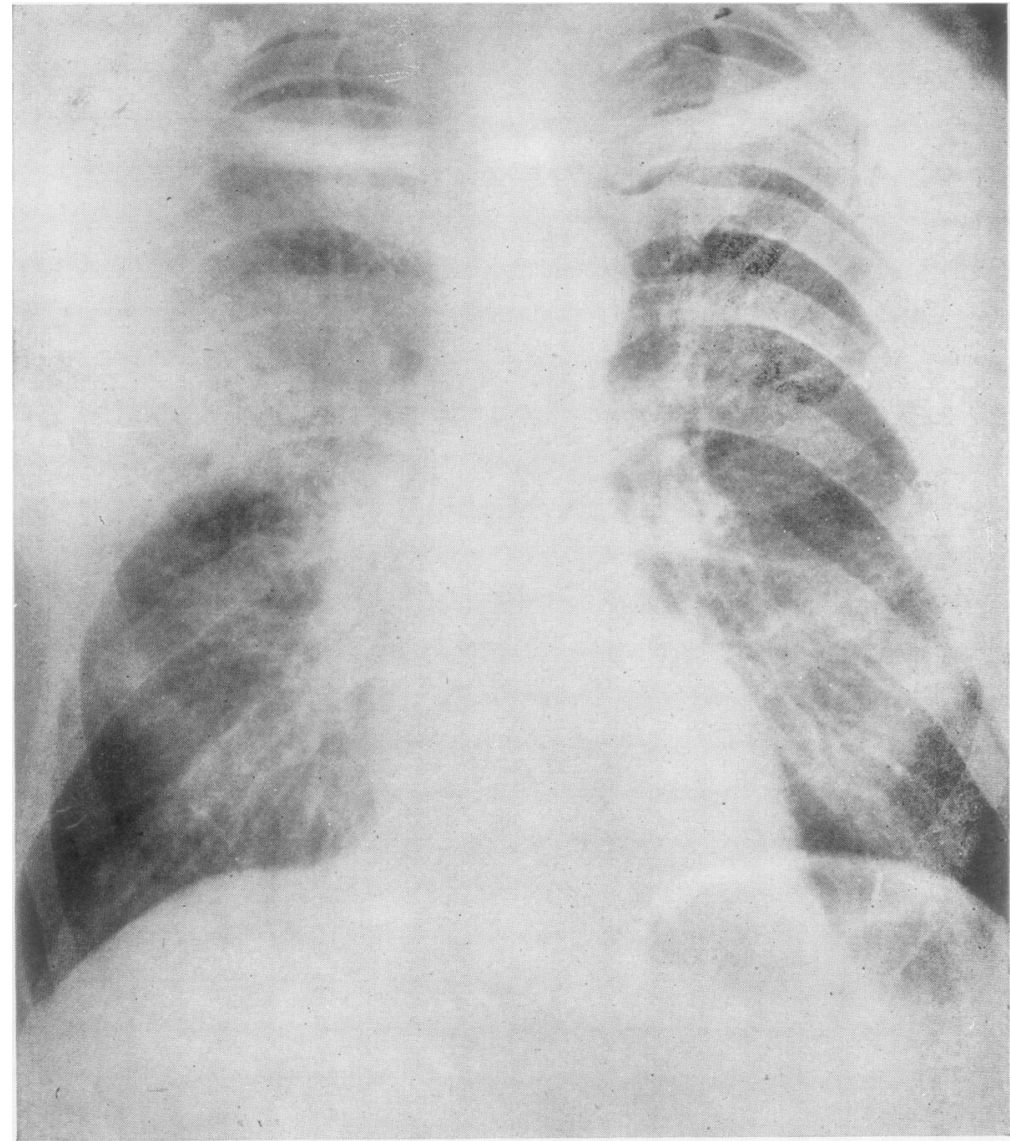

FIG. 6.-Case 108, P.A. view, November 13, 1946. Opacity in upper half of right lung 10 days after onset.

although the proportion of " network" and nodules varied in different areas of the same lung. In patients 104 (Fig. 4), 110 (Fig. 5), 108 (Fig. 7), 121 (Fig. 8) and 128 the nodules were so widespread and numerous as to suggest miliary tuberculosis. In patients 107 and 120 , the infiltration was less extensive. In patient 105 the reticular pattern was the more pronounced. Whichever form of opacity, nodules or reticulation, was the more prominent, the bases of the lungs were most frequently affected.

The infiltration was remarkably widespread. In two patients, 108 and 121, the lesions were scattered throughout both lungs: in patients 104,110 , and 128 the whole of one lung and a considerable portion of the other lung were involved. In the remaining patients 105,107 , and 120 , large areas of both lungs were affected.

Spread of the pneumonic process was observed in several cases. In the initial film of patient 108 the right upper zone presented many nodules aggregated into a large dense granular opacity, with individual nodules apparent toward the periphery (Fig. 6). Improvement in the patient's general condition was followed on the nineteenth day of illness, eight days after the initial radiograph, by a sudden exacerbation of symptoms and considerable extension of physical signs. Radiography 25 days after onset revealed apparent resolu . tion of the opacity in the right upper zone, and nodules throughout both lungs, with lessened translucency. Enlarge ment of the heart, noted clinically for several days, was also evident in this film (Fig. 7). The patient died on the twenty-seventh day of illness. and the miliary appearance was attributed to extensive endobronchiolitis and intersti tial pneumonia rather than to venous congestion. Patients 107, 110, and 121 showed extension of a predominantly nodular lesion in serial films.

Accompanying these pulmonary lesions, one hilar shadow was enlarged in patients 105 and 128. In patients 107 and 121 , the heart was displaced to the left, and the left diaphragm was elevated. In patient 107 there was a lso a dense opacity, triangular in shape, with defined edges, suggesting segmental collapse at the base of the left lung. When the diaphragm and heart returned to their normal positions in subsequent films, this opacity was replaced by several "atelectatic plates," and still other areas of atelectasis appeared at the left base. Patient 121 (Fig. 8) showed considerable displacement of the heart to the left with elevation of the left diaphragm. The lower third of the left lung was obscured by a hazy opacity, of moderate density in its upper part, but very dense in its lower portion. Serial films showed the gradual return of heart and diaphragm to their normal positions, the basal opacity decreased in extent and density, ird the vascular and lung markings reappeared two months after onset. The next examination, four 
months after onset, showed tenting at the anterior and medial part of the left diaphragm, which was still present 16 months later.

In the initial A.P. film of patient 105 , obtained 12 days after onset, there were two fine, parallel, linear opacities in the lower half of the right lung. These opacities began just lateral to the cardiophrenic angle, and extended in a slightly curved fashion, with the concavity toward the hilum, to the region of the middle of the transverse fissure. A P.A. film taken a fortnight later, when the reticular opacity had almost resolved, showed that the two lines had been replaced by one wider linear opacity, tapering at its upper extremity, in the same site. Subsequent films four, 13, and 19 months after onset no longer showed this linear opacity, but a few abnormal markings persisted at the base of the left lung. Linear opacities of a similar unusual type were recorded by Finland, Ritvo, Davidson, and Levenson (1946) and were attributed by them to atelectasis.

Resolution soon followed recovery from the acute illness, and progressed by diminution in number and density of the nodules, return of the normal translucency, and a slower decrease of the reticulation. As the reticulation waned, there remained accentuation of the normal lung markings. These slowly subsided over further examinations.

Adhesions affecting the middle portion of the diaphragm became apparent in four patients during resolution. The left side was affected in patient 121 , and the right side in patients 104, 110, and 128. An initial A.P. film of patient 110, obtained 18 days after onset, showed an aggregation of nodules at the base of the right lung. Lateral films a week later showed the right diaphragm to be elevated in its mid-portion, with infiltration of the lung above, and a crowded leash of broncho-vascular markings ascending to the right hilum. In later films, resolution of this infiltration showed a small "tent" of diaphragm in this area, five weeks after onset. Examination three and ten months after onset showed no abnormality except prominence of the peripheral lung markings in each lower zone.

The radiological findings are summarized in Table I. The unusually high proportion of patients presenting a disseminated focal type of pneumonia, in most instances associated with a severe illness, was probably due to the selection of the more ill patients for admission to a busy public hospital. The study was hampered by the absence of chest films taken before the onset of the illness, the frequency of severe illness and rapid respirations, and shortages of films from time to time. In most patients it was not possible to determine precisely which lobes of the lung were involved.

Certain features which were prominent in this study have not been emphasized in other reports. These were the frequent evidence of atelectasis, the formation of diaphragmatic adhesions, and the prolonged persistence of exaggerated lung markings. In general, the more severe and prolonged the acute illness, the slower was resolution, and the more protracted was convalescence by persisting cough, asthenia, and shortness of breath on exertion. Resolution usually advanced at a varying pace to a stage at which accentuated lung markings, often accompanied by prominent vascular markings remained. From this stage, it slowly continued, but although in many patients the appzarance of the lungs became normal, and in some tenting of the diaphragm became less apparent or disappeared, resolution was not complete in four patients at the end of the period of observation.

The tendency of the pulmonary lesions of primary atypical pneumonia to resolve slowly, the persistence of abnormal pulmonary markings, and the formation of diaphragmatic adhesions are indicative of organization of the inflammatory products in part. Golden (1944) described the interspersion of mild and severe bronchiolar lesions. In the latter, he was impressed by the dilatation of the bronchioles, the destruction of the elastic fibres, the fragmentation of the muscle bundles and shredding of the reticular network. It was considered that such lesions could heal only with persistent dilatation and scar formation, although this did not of necessity imply that such lesions would or could be clinically manifest as chronic bronchiectasis. In other areas of the lungs, a not infrequent feature was masses of fibrin, occasionally seen undergoing organization, filling alveoli and taking their shape.

Parker, Jolliffe, and Finland (1947) considered that polymorphonuclear exudate within the bronchiolar lumen was the result of secondary bacterial infection, and that injury to the bronchiolar mucosa is not a feature of primary atypical pneumonia. In their series, organization of the alveolar and bronchiolar exudates was found in the majority of cases but was not extensive.

In the lungs of the two fatal cases seen in Adelaide (Verco, 1949; Fowler and French, 1949), the bronchiolar plugs within the same area appeared to vary greatly in age. Some were recent with polymorphonuclear exudate, whereas in neighbouring bronchioles organization of the plugs was advanced, although death occurred seven days after the onset of the illness in one patient, and nine days after extensive spread of the process in the other (Fig. 9). 


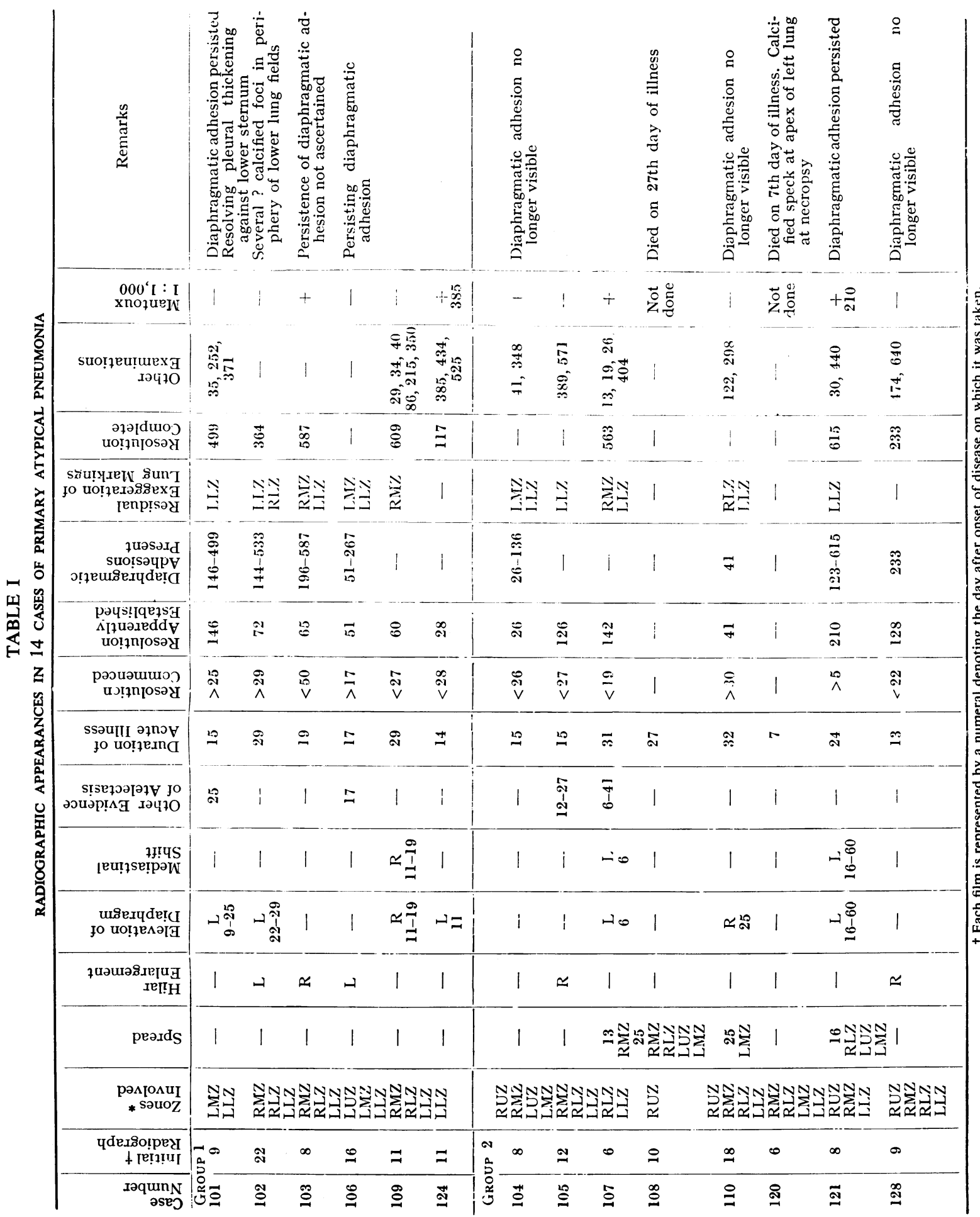


Further, in the peribronchiolar and other alveoli of both patients, organization, although not extensive, was proceeding (Figs. 10 and 11). In other respects the histological lesions in the lungs of these two patients were very similar to those described by Golden.

These histological findings suggest that delay in resolution in primary atypical pneumonia with persisting symptoms may well be due to local obliterative bronchiolitis, fibrosis in the bronchiolar wall, and organization within the alveoli.

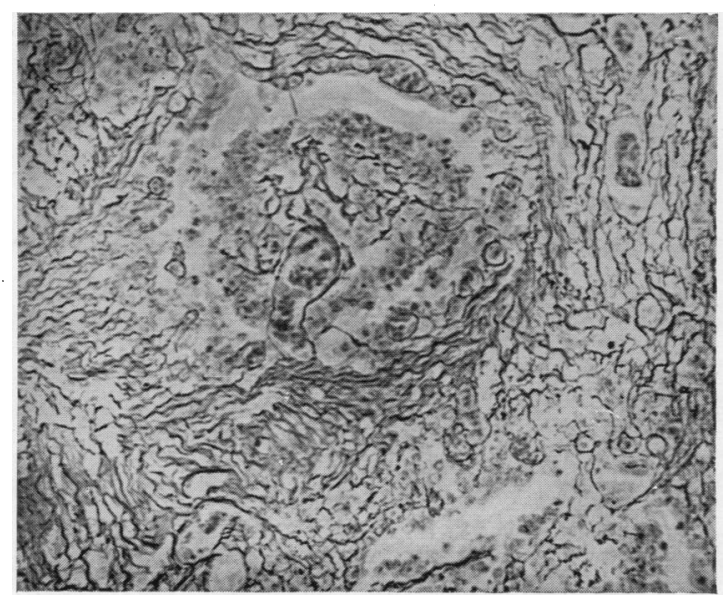

FIG. 9.-Case 108. Photomicrograph of section stained with Krajian's reticulum stain showing organization within bronchiole with recently formed collagen fibres. $\times 210$.

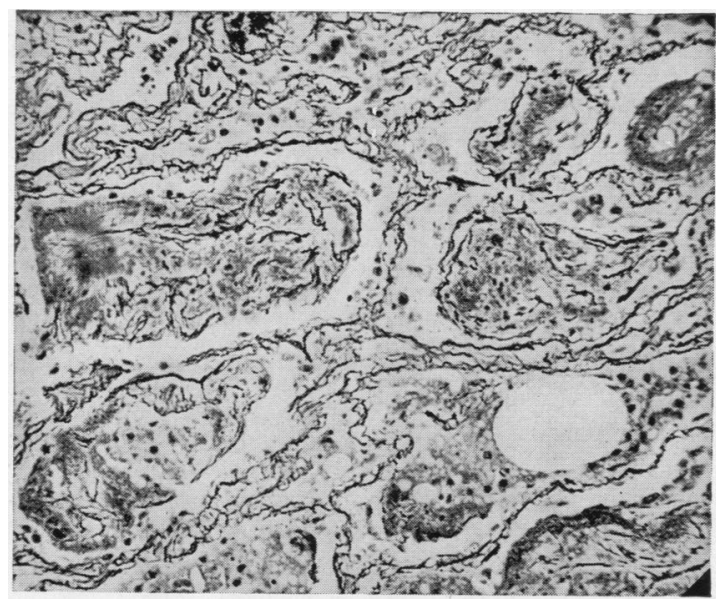

FIg. 10.-Case 108. Photomicrograph of section stained with Krajian's reticulum stain showing organization of alveolar exudate with recently formed collagen fibres within the alveoli. $\times 175$.

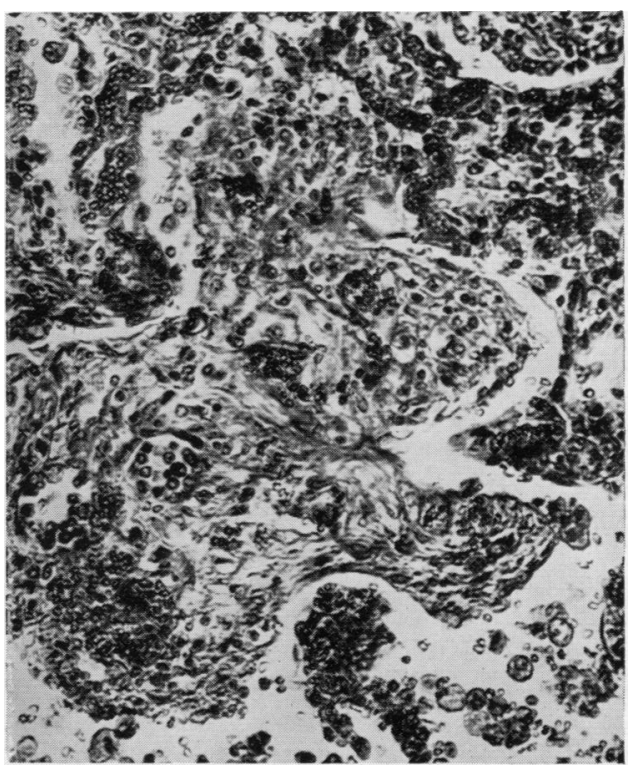

FIG. 11.-Case 120. Photomicrograph stained with Masson's trichrome stain showing organization within alveoli, probably of a protruding bronchiolar plug. $\times 175$.

\section{Differential Diagnosis}

In the first group of six patients the course of the illness was not severe, and the radiological lesions were of the form which usually accompanies primary atypical pneumonia. This more compact, localized form of opacity may mimic many other diseases, not only as it develops, but when at its maximum, and again in resolution. Previous observers have emphasized that other forms of pneumonia, not the least among which was pulmonary tuberculosis, could not be distinguished from primary atypical pneumonia on the basis of radiographic evidence alone, as the shadows were not distinctive of this condition exclusively.

In the experience of most observers, the widely disseminated, focal form of pneumonia observed in the second group of eight patients has been associated with a severe and prolonged course. The differential diagnosis of these "disseminated focal " cases will be considered in more detail.

The pulmonary lesions of acute miliary tuberculosis are small, of uniform size, and evenly distributed throughout the lungs. Acino-nodular forms of tuberculosis usually complicate pre-existing pulmonary tuberculosis and are seldom seen in pure form for any length of time. Miliary forms of pneumonia have been described accompanying measles, chickenpox (Waring, Neubuerger, and Geever, 1942), epidemic influenza (Shore, 1918), 
pertussis (Caffey, 1945; Lapin, 1943), acute bronchiolitis in children (Paul, 1941), brucellosis (Austrian and Brown, 1942), and tularaemia (Archer, Blackford, and Wissler, 1935), and due to haemolytic streptococci (Ellman, 1946). Pneumonia of this distribution is apparently not produced by the psittacosis group of viruses or by Rickettsia burneti, though it may appear in the later stages of scrub typhus. Chemical pneumonia may be delayed in onset, or may follow immediately the inhalation or aspiration of noxious material. In irrespirable gas intoxication the picture resembles that of acute pulmonary oedema, except that the nodules are more distinct and the cardiac silhouette is unaltered; in the presence of secondary infection the roentgen findings may alter considerably (Rubin, 1947). Finland and others (1946) encountered similar opacities among victims of the Cocoanut Grove fire in Boston. The acute pulmonary disease which may follow inhalation of fumes arising from the heat processing of beryllium (van Ordstrand and others, 1945) and cadmium (Paterson, 1947) may cause miliary shadows. Aluminium pneumoconiosis (Shaver and Riddell, 1947) is said to arise as a result of breathing concentrations of powdered aluminium over periods as short as three months. Lipoid pneumonia, aspiration pneumonia consequent upon a disorder of swallowing, or the pulmonary lesions accompanying cardiospasm may assume a diffuse nodular form (Hawes and Soule, 1945).

In individuals subject to asthma, transient disseminated foci of opacity may be associated with a high percentage of eosinophils in the circulating blood. A similar form of pulmonary opacity accompanies "tropical eosinophilia" (Hodes and Wood, 1945), and may be present in periarteritis nodosa (King, 1938), erythema multiforme exudativum (Kneeland and Smetana, 1940), and disseminated lupus erythematosus (Austrian and Brown, 1942). Coccidioidomycosis (Rakofsky and Knickerbocker, 1946) and histoplasmosis (Colvin, Gore, and Peters, 1944) may produce miliary lesions in the lungs. Fawcitt (1938) described an occupational hazard of agricultural workers associated with infections by a number of fungi; a frequent radiological finding was a rather soft, snow-flake mottling, widely distributed throughout both lungs, with a tendency for the mid-lung fields and bases to be more affected than the apices. Törnell (1946) described miliary disease of the lungs accompanying infection with monilia. It is suspected that the miliary mottlings in the lungs of bagasse workers (Lemone and others, 1947) are due to organisms, probably fungi, attached to the fibres of bagasse (Gerstl and others, 1947).
La Due (1941) has reported a case of bronchiolitis fibrosa obliterans, which presented a focal disseminated form of opacity. Toxoplasmosis has been reported in Australia (Robertson, 1946); the description of the pulmonary lesions by Pinkerton and Henderson (1941) is of interest. Other conditions which might conceivably present confusion are pulmonary metastases of malignant disease, irradiation pneumonitis (Widmann, 1942), the pneumoconioses, sarcoidosis (Garland, 1947), bronchiectasis and cystic disease of the lungs, alveolar filling with iodized oil, endogenous pulmonary siderosis (Scott and others, 1947), pulmonary ossification accompanying mitral stenosis (Elkeles and Glynn, 1946), the pneumonia accompanying acute rheumatic fever (Mossberger, 1947), miliary gummata in syphilis, purpura, schistosomiasis (Shanks and others, 1938), miliary leprosy (Deland, 1948), polycythaemia vera, and the pulmonary changes in scleroderma (Rubin, 1947; Lloyd and Tonkin, 1948), the xanthomatoses, and tuberose sclerosis (Berg and Nordenskjöld, 1946).

\section{Discussion}

Aetiology.-Among the many descriptions of epidemic and endemic primary atypical pneumonia, few are accompanied by adequate aetiological investigation (Commission on Acute Respiratory Disease, 1944 and 1946; Meiklejohn, 1947; Curnen and others, 1945; Eaton and others, 1942).

Scadding (1948) has reviewed the literature on this subject. He has suggested that in many reports case histories and radiographs were consistent with a segmental collapse. This might well be that type of atelectasis described by Ramsay and Scadding (1939), believed to result from infected mucus of nasal or bronchial origin obstructing bronchi or bronchioles. This phenomenon is of sporadic occurrence, and associated with acute or chronic catarrh of the respiratory tract.

The Commission on Acute Respiratory Diseases (1946) were able to transmit " primary atypical pneumonia " to human volunteers, using filtered throat washings and sputum. The high associated incidence of acute upper respiratory tract infections in the recipients indicated that probably several virus infections were transmitted. More recently, an illness like the common cold, another illness resembling the acute pharyngitis of recruits, and $\stackrel{\oplus}{\rightarrow}$ "primary atypical pneumonia" were transmitted 0 to human volunteers. Subsequent challenge experiments have provided some evidence of the individuality of these virus diseases (Commission on Acute Respiratory Diseases, 1947). These experiments strongly suggest that primary atypical 
pneumonia is caused by a virus or viruses. The difficulties of this sort of work are great: attempts to procure experimental transmission to man of virus influenza and the common cold have been remarkable for failures and difficulty in obtaining "takes," and the resulting illness has usually been mild. Eaton, Meiklejohn, and van Herick (1945) transmitted a virus from cases of primary atypical pneumonia to chick embryos by inoculation with suspensions of bacteriologically sterile lung tissue or filtered sputum. Strains of this virus have been adapted by passage to infect cotton rats or hamsters by intranasal inoculation, causing pulmonary lesions. Considerable difficulty was experienced because of contamination with latent respiratory viruses already present in the animals. The agent propagated in the chick embryos was specifically neutralizable by the sera of patients convalescent from primary atypical pneumonia, but not by acute phase sera. This virus seems fairly well established as a cause of disease in man, and Eaton has estimated that it accounts for a considerable portion of cases of primary atypical pneumonia (1945). Breslow (1945) studied clinically an outbreak of acute respiratory disease associated with atypical pneumonia in which there was serological evidence of infection by this virus. The illness was generally mild, and only a small proportion of cases showed clinical evidence of pneumonia. He concluded that the disease was probably not primarily a pneumonia: the designation "atypical pneumonia" seemed to exaggerate what was probably only an incident in the disease.

Evidence obtained by transmission experiments and in aetiological studies strongly supports a virus or viruses as the cause of this condition. It is not improbable that the same agent should be responsible for the two forms of pulmonary opacity, which are associated with very similar clinical and laboratory findings. The radiological lesions, while falling into two groups, have certain likenesses, gradations between the two groups occur, and the compact localized form of opacity has been followed by disseminated focal spread in the same patient (Figs. 6 and 7). Cases of the disseminated focal form of pneumonia have occurred as a minority in epidemics of primary atypical pneumonia, and similar pulmonary lesions were present in several cases of experimentally transmitted disease (Commission on Acute Respiratory Diseases, 1946).

Pulmonary Changes in Long Incubation Period Virus Diseases.-Both forms of opacity accompany long incubation period virus diseases, notably measles, and occur at a period when superimposed secondary infection is unlikely. Though the frequent involvement of the lower portions of the lungs in primary atypical pneumonia has been accepted as evidence of infection and spread by the air passages, a rather similar distribution of the lobes involved occurs in measles pneumonia.

Kohn and Koiransky (1929) have drawn attention to the early and frequent pulmonary involvement present in the eruptive and pre-eruptive stages of measles in children. On radiography this was manifest in nearly all the cases of one study (Kohn and Koiransky, 1933) as enlargement of the lymph nodes about the tracheal bifurcation, and was most readily detected in lateral films. Pulmonary infiltration occurred in some 60 per cent of cases, and was either widely disseminated or more localized. Pleural involvement was frequently shown by visibility of the fissures between the lobes: in some cases substantial opacities were seen in these situations and against the anterior chest wall. A post-mortem radiograph of the lungs from a child dying with the widely disseminated focal form of measles pneumonia revealed innumerable small dense opacities of varying size scattered throughout both lungs, without much tendency to coalesce or form large confluent areas. Histologically, the lesions were comparable with those of primary atypical pneumonia described by Golden (1944). Compared with a radiograph of the lungs of a child who died of miliary tuberculosis, the nodules in measles are larger, of less uniform size, and not so evenly distributed throughout the lungs.

Milles (1945) recorded the deaths of two adults from measles, and noted the radiographic resemblance of the disseminated bronchiolitis, peribronchiolitis, and bronchopneumonia of measles to miliary tuberculosis and to some cases of primary atypical pneumonia.

Waring, Neubuerger, and Geever (1942) recorded two cases of pneumonia accompanying severe chickenpox in adults, with one fatality. The pneumonia in the fatal case was of virus type, and in both cases radiography five and six days after the onset revealed " widespread mottling" or innumerable small shadows throughout both lungs, similar to certain cases of pneumonia accompanying measles. Both cases were thought to be examples of primary pneumonia due to the virus of chickenpox, although the non-fatal case was complicated by secondary infection with a haemolytic streptococcus.

Evidence has been presented by the Commission on Acute Respiratory Diseases (1946), that the incubation period of primary atypical pneumonia is from seven to fourteen days when transmitted to human volunteers. This minimal incubation period of seven days is much longer than one would expect 
in a purely local respiratory disease such as influenza, in which the incubation period is about two days.

In primary atypical pneumonia the widespread pulmonary lesions, often symmetrical, are very similar to those seen in the primary pneumonias of the long incubation period virus diseases, measles and chickenpox, and may resemble in distribution those of miliary tuberculosis. This suggests analogous dissemination of the causative organism by the blood stream, although " thresher's lung," an acute miliary pneumonia caused by monilia, apparently results from extensive airborne infection from mouldy grain while threshing (Törnell, 1946). In primary atypical pneumonia enlargement of the spleen sometimes occurs, and in an acute febrile illness this of itself suggests haematogenous spread. The occurrence of leucoencephalitis, as in patient 120 , and of a haemolytic anaemia with myeloid primitive cells in patient 105 , together with symptoms of meningeal involvement with an increased cellular content of the cerebrospinal fluid, are suggestive of a general systemic disease. The occurrence of cold agglutinins and of " $T$ " agglutinins, like heterophil agglutinins in mononucleosis, indicates the presence of some widespread interference with the globulinproducing mechanism.

These features suggest that primary atypical pneumonia may be a general systemic disorder which almost invariably localizes in the lungs. It may be that there is a primary localized focus of infection in the respiratory tract, which may either spread directly along the mucous membranes to produce a rather extensive local consolidation, or may be followed by invasion of the blood stream via the regional lymph nodes. Most frequently, perhaps, both modes of spread would occur. The widely disseminated lung lesions may follow the period of viraemia directly; or probably there is, as Fenner (1948) has postulated for the acute exanthemata, a period of multiplication of virus in the cells of the reticulo-endothelial system in the spleen and elsewhere before sufficient virus is freed into the blood stream to cause the widely scattered foci in the lungs. There is no doubt that other factors such as the amount of the infecting agent, its invasiveness and virulence, the general and local resistance of the infected host, and the presence of hypersensitivity or allergy to the infecting agent determines the distribution and extent of the resulting lesion.

Incomplete Resolution.-In this series of cases, patients in the first group were only moderately ill. A severe and prolonged course was frequent in the second group, and there were two fatalities. Resolution followed subsidence of the acute symptoms in both groups, but in many cases accentuated lung markings persisted in the affected areas. In several patients tenting of the central portion of one diaphragm was disclosed, although there was no sensitivity to the Mantoux test. Subsequently, the abnormal lung markings and diaphragmatic adhesions disappeared in some patients, but in others remained throughout the period of observation.

The two fatal cases had been treated with penicillin intramuscularly. The lungs of patient 120 were bacteriologically sterile at necropsy, and bacteria were not seen in the sections, but areas of polymorph exudate which were not within the bronchioles and suggesting secondary bacterial infection, were present in the lungs. Such areas were few and of small extent in patient 108. Despite the short duration of the illness in one patient, and recent spread of the process in the other, some bronchiolar plugs were in a state of advanced organization, and fibroblasts with newly formed fibres of collagen were present amid the exudate of mononuclear cells in some peribronchiolar and other alveoli.

Though the organization was not extensive in these cases, it has been observed in similar cases by Golden (1944) and Parker, Jolliffe, and Finland (1947). In this series the early organization is considered to be responsible for the delay in resolution with persisting accentuated lung markings, for the appearance of diaphragmatic adhesions, and to favour the conception that, like measles and influenza, primary atypical pneumonia may lead to residual pulmonary fibrosis.

\section{SUMMARY}

The radiological features of a series of 14 cases of primary atypical pneumonia were studied. The majority of these cases occurred during an epidemic. Aetiological studies were carried out. The clinical, radiological, and laboratory features closely resembled those described in this condition by other observers, as did the histology of the lungs in the two fatal cases.

In six patients the opacities in the radiographs of the lungs were localized. In the remaining eight, the radiographs indicated lesions in widely disseminated foci; these patients were more ill, and two of them died. In five patients of this group, the radiological features suggested acute miliary tuberculosis.

During resolution which followed subsidence of the acute symptoms, tenting of the central portions of either half of the diaphragm was disclosed in certain patients. As resolution advanced, abnormally increased lung markings persisted for varying periods, and in four patients were still present at 
the termination of the study. The persisting lung markings and the formation of diaphragmatic adhesions were taken as evidence of residual fibrosis, and histological confirmation was obtained from both fatal cases.

My thanks are due to the honorary and technical staff of the Radiological Section of the Royal Adelaide Hospital for help and criticism in carrying out this investigation, and to Mr. L. N. Jones for reproducing the radiographs.

\section{REFERENCES}

Adams, J. M. (1941). J. Amer. med. Ass., 116, 925.

Allen, F. H., and Kellner, A. (1947). Amer. J. Path., 23, 463.

Archer, V. W., Blackford, S. D., and Wissler, J. E. (1935). J. Amer. med. Ass., 104, 895.

Austrian, C. R., and Brown, W. H. (1942). Amer. Rev. Tuberc., 45, 751.

Berg, G., and Nordenskjöld, A. (1946). Acta med. scand., 125, 428.

Breslow, L. (1945). J. clin. Invest., 24, 775.

Caffey, J. (1945). Pediatric X-Ray Diagnosis, The Year Book Publishers, Chicago, 264.

Claudy, W. D. (1947). Arch. intern. Med., 80, 185.

Colvin, S. H., Gore, I., and Peters, M. (1944). Amer. J. med. Sci., 207, 378.

Commission on Acute Respiratory Diseases (1944). Amer. J. Hyg., 39, 67, 197, 298. (1946). Bull. Johns Hopk. Hosp., 79, 97. (1947). J. clin. Invest., 26, 957.

Curnen, E. C., Mirick, G. S., Ziegler, J. E., Thomas, L., and Horsfall, F. L. (1945). J. clin. Invest., 24, 209.

Deland, C. M. Personal communication.

Drew, W. R. M., Samuel, E., and Ball, M. (1943). Lancet, 1, 761.

Eaton, M. D., (1945). Calif. Med., 26, 957.

- Meiklejohn, G., and van Herick, W. (1945). J. clin. Invest., 24, 241.

and Talbot, J. C. (1942). Science, 96, 518.

Elkeles, A., and Glynn, L. E. (1946). J. Path. Bact., 58, 517.

Ellman, P. (1946). Brit. med. J., 1, 127.

Fawcitt, R. (1938). Brit. J. Radiol., n.s., 11, 378.

Feinstein, M., Yesner, R., and Marks, J. L. (1946). Amer. J. Hyg., 44, 72.

Fenner, F. (1948). Lancet, 2, 915.

Finland, M., Ritvo, M., Davidson, C. S., and Levenson, S. M. (1946). Amer. J. Roentgenol,, 55, 1.

Fowler, M., and French, E. L. (1949). Med.J. Australia, $1,267$.

Garland, L. H. (1947). Radio'ogy, 48, 333.

Gerstl, B., Tager, M., and Marinaro, N. A. (1947). Arch. Path., 44, 343.

Golden, Alfred (1944). Arch. Path., 38, 187.

Hawes, L. E., and Soule, A. B. (1945). Amer. J. Roentgenol., 53, 124.

Hodes, P. J., and Wood, F. C. (1945). Amer. J. med. Sci., 210, 288.

Jamison, H. W. (1945). Radiology, 45, 15.

King, D. S. (1938). New International Clinics, 1, 115.

Kneeland, Y., and Smetana, H. F. (1940). Bull. Johns Hopk. Hosp., 67, 229.

Kohn, J. L., and Koiransky, H. (1929). Amer. J. Dis. Child., 38, 258.

— (1933). Ibid., 46, 40.
La Due, J. S. (1941). Arch. intern. Med., 68, 663.

Lapin, J. H. (1943). Whooping Cough. Charles C. Thomas, Springfield, Illinois.

Lemone, D. V., Scott, W. G., Moore, S., and Link Koven, A. (1947). Radiology, 49, 556.

Lewis, E. K., and Lusk, F. B. (1944). Radiology, $42,425$.

Lind, P. E., and McArthur, N. R. (1947). Aust. J. exp. Biol. med. Sci., 25, 247.

Lloyd, W. E., and Tonkin, R. (1948). Thorax, 3, 241.

Löffler, W., and Moeschlin, S. (1946). Schweiz. med. Wschr., 76, 815.

McCarthy, Paul V. (1943). Radiology, 40, 344.

McCordock, H. A., and Muckenfuss, R. S. (1933). Amer. J. Path., 9, 221.

McIntosh, H. C., and Spitz, S. (1939). Amer. J. Roentgenol., 41, 605.

Meiklejohn, G. (1947). Med. Clin. N. Amer., 31, 1442.

Milles, G. (1945). Amer. J. clin. Pxth., 15, 334.

Mossberger, J. I. (1947). J. Pediat., 30, 113.

Parker, F., Jolliffe, L. S., and Finland, M. (1947). Arch. Path., 44, 581.

Paterson, J. C. (1947). J. industr. Hyg., 29, 294.

Paul, L. W. (1941). Amer. J. Roentgenol., 45, 41.

Pinkerton, H., and Henderson, R. G. (1941). J. Amer. med. Ass., 116, 807.

Rakofsky, M., and Knickerbocker, T. W. (1946). Amer. J. Roentgenol., 56, 141 . .

Ramsay, H., and Scadding, J. G. (1939). Quart. J. Med., n.s., 8, 79.

Reimann, H. A. (1938). J. Amer. med. Ass., 111, 2377.

Robertson, E. G. (1946). Med. J. Australia, 2, 449.

Rubin, E. H. (1947). Diseases of the Chest, W. B. Saunders Co., Philadelphia.

Scadding, J. G. (1937). Brit. med. J., 2, 956.

- (1948). Lancet, 1, 89.

Scott, L. W. D., Scott Park, S. D., and Lendrum, A. C. (1947). Brit. J. Radiol., n.s., 20, 100.

Shanks, S. C., Kerley, P., and Twining, E. W. (1938). Text-book of X-ray Diagnosis by British Authors, 1, London.

Shaver, C. G., and Riddell, A. D. (1947). J. industr. Hyg., 29, 145.

Shore, T. H. G. (1918). Special Report Series, No. 36, 96. London.

Showacre, E. C., Wightman, H. B., and Moore, N. S. (1944). N.Y. St.J. Med., 44, 872.

Smadel, J. E., Green, R. H., Paltauf, R. M., and Gonzales, T. A. (1942). Proc. Soc. exp. Biol., N.Y., 49, 683 .

Törneli, E. (1946). Acta med. scand., 125, 191.

Treuting, W. L., and Olson, B. J. (1944). Publ. Hlth Rep., 59, 1331 .

van Ordstrand, H. S., Hughes, R., de Nardi, J. M., and Carmody, M. G. (1945). J. Amer. med. Ass., 129, 1084.

Verco, P. W. (1949). Med. J. Australia, 1, 254.

Waring, J. J., Neubuerger, K., and Geever, E. F. (1942). Arch. intern. Med., 69, 384.

Wechsler, H. F., Rosenblum, A. H., and Sills, C. T. (1946). Ann. intern. Med., 25, 113.

Widmann, B. P. (1942). Amer. J. Roentgenol., 47, 24.

Winternitz, M. C., Wasson, I. M., and McNamara, F. P. (1920). Pathology of Infuenza, Yale University Press, New Haven, Connecticut.

Ziegler, J. E., Curnen, E. C., Mirick, G. S., and Horsfall, F. L. (1947). Amer.J. med. Sci., 213, 268. 